\title{
The Worksite Environment as a Cue to Smoking Reduction
}

\author{
Karen M. Conrad, Richard T. Campbell, D.W. Edington, \\ Halley S. Faust, and Douglas Vilnius
}

\begin{abstract}
With a modified version of the Health Belief Model as the conceptual framework, the hypothesis that exposure to a worksite health-promoting environment acted as a cue to smoking reduction among 310 smokers was tested with a quasi-experimental design. Using path analysis (LISREL), the total effects on posttest smoking were decomposed. Results showed exposure to the healthpromoting environment had statistically significant direct and indirect effects on posttest smoking. The indirect effect was through the posttest perceived barriers variable. The LISREL model explained $74 \%$ of the variance in smoking reduction and fit the data satisfactorily. The importance of developing the worksite as a health-promoting force is discussed. (c) 1996 John Wiley \& Sons, Inc.
\end{abstract}

Cigarette smoking takes a sizable financial toll on American business and a devastating toll on the lives of the millions of American workers who smoke (United States Department of Health and Human Services [USDHHS], 1990). In 1990 alone, the price tag to the nation for smoking was $\$ 72$ billion (Institute for Health Policy, Brandeis University, 1993). Today, 30 years after the release of the landmark Surgeon General's report that clearly linked cigarette smoking with death and disease (United States Public Health Service [USPHS], 1964), nearly one third of all workers continue to smoke (Nelson et al., 1994). The smoking prevalence rate in some occupations still exceeds 50\% (Nelson et al., 1994).

Worksite health promotion programs have evolved as one approach to help employees reduce their personal health risks (USDHHS, 1993). Researchers have typically examined the health effects of formalized intervention programs, such as smoking cessation, on program participants' lifestyle behaviors. Based on their meta-analysis of controlled worksite smoking cessation programs, Fisher, Glasgow, and Terborg (1990) concluded that such programs are generaliy efficacious in the short term. However, the long-term quit rates of formalized smoking cessation programs are disappointingly low (McIlvain, McKinney, Thompson, \& Todd, 1992). Most smokers quit on their own without the benefit of a formal program (Fielding, 1986).

An alternative public health approach is to consider the effectiveness of the worksite environment as a health-promoting force to alter personal health risks. This latter approach allows for an examination of the worksite as a context for promoting worker health. It also permits an assessment of health effects on a wider target group, because the treatment group may be viewed as all workers with a given risk factor exposed to a health-promoting environment instead of only those who participate in a formal program intervention (Glynn, Boyd, \& Gruman, 1990). To date, little is known about the characteristics of the worksite environment that may be associated with successful smoking outcomes (Glasgow, Sorenson, \& Corbett, 1992).

Karen M. Conrad, PhD, MPH, RN, is an associate professor, Department of Public Health, Mental Health, and Administrative Nursing; and Richard T. Campbell, PhD, is a professor, Department of Sociology, University of Illinois, Chicago. D.W. Edington, PhD, is director of the Fitness Research Center, University of Michigan; Halley S. Faust, MD, is President, Med Max, Inc., West Hartford, Connecticut; and Douglas Vilnius, MS, is Director, Division of Community Health Services, Utah Department of Health.

This article was received August 4, 1993, revised, and accepted for publication on May 24, 1995.

Requests for reprints can be addressed to Dr. Conrad, Public Health, Mental Health, and Administrative Nursing (M/C 802), University of Illinois at Chicago, 845 South Damen Avenue, Chicago, IL 60612-7350. 
With an environmental intervention, the intervention of interest is not restricted to an educational or clinical program for smoking cessation or reduction. Rather, the intervention of interest may include a host of company strategies and initiatives that create a health-promoting environment supportive of smoking reduction or cessation. Here, the worksite environment is used to provide sustained, high-level, nonsmoking cues (Flay, 1987). Glynn et al. (1990) defined cues as "any activity, policy, or message which catches the attention of smokers and makes them dwell, however briefly, on the negative aspects of smoking or positive aspects of nonsmoking and the decision to quit or not" (p. 337). The treatment group is all smokers in the company exposed to the health-promoting environment. This group can then be compared to smokers not exposed to this environment.

Given the enormity of the smoking problem, it is important to target worksite intervention efforts at this broader audience of all smokers rather than only the small minority of workers who are ready to engage in a formalized program. Examination of the potential health and cost effectiveness of worksite environmental health promotion interventions is rare. However, within the past few years, a growing interest in this type of investigation has begun to surface in the worksite health promotion literature (Glasgow, Hollis, Ary, \& Boles, 1993; Jeffery et al., 1993; Hymowitz, Campbell, \& Feuerman, 1991; Shipley, Orleans, Wilbur, Piserchia, \& McFadden, 1988; Sorenson, Lando, \& Pechacek, 1993). The small research base precludes drawing any firm conclusions about the effects of worksite environmental approaches, although with some exceptions, the results to date are positive (Hymowitz et al., 1990).

The objectives of this study were (a) to examine whether a broad-based worksite health-promoting environment acted as a cue to smoking reduction among workers, and (b) if the environment did act as a cue, then to explore whether the environment promoted smoking reduction by altering selected personal health beliefs.

The Health Belief Model (HBM) was adapted for use in this study. The HBM (Becker \& Maiman, 1975; Rosenstock, 1966) posits that an individual's health-related behaviors, such as smoking, can be predicted by several beliefs: the individual's perceived susceptibility to a condition or disease, the perceived seriousness of the condition or disease, and the perceived benefit of some named preventive action minus any perceived barriers. Perceived susceptibility and per- ceived seriousness combine to put the individual into a readiness-to-act state. The perceived benefits minus the perceived barriers indicate the preferred pathway to action. These four HBM variables are considered the core variables. Finally, a cue, defined as an internal or external stimulus or instigating event, is needed to trigger the person into action. The cue-to-action variable has been discussed frequently but has not been systematically studied, even though it may ultimately prove to be important (Knight \& Hay, 1989; Stacy \& Loyd, 1990; Rosenstock, 1990).

In this study, the HBM was adapted by postulating that the cue-to-action variable (i.e., the worksite health-promoting environment) would not only trigger smoking reduction as the HBM proposes, but that it would also act to alter health beliefs. The literature on smoking contains few smoking behavior studies based on the HBM. Published studies are largely cross-sectional and have focused on examining the correlations between core health beliefs and smoking. Longitudinal causal models were not tested in these studies, even though they are a more appropriate method, given that the HBM postulates causal relationships between beliefs and behavior (Chen \& Land, 1986).

The following hypotheses were tested: (a) pretest health beliefs, smoking behavior, and exposure to a health-promoting environment will have direct effects on posttest smoking reduction and indirect effects on smoking reduction via posttest health beliefs; and (b) posttest health beliefs will have direct effects on posttest smoking behavior. Placement of the posttest health belief variables as intervening variables in the model permitted tests of how the program worked; that is, whether the exposure to the health-promoting environment altered health beliefs and whether any of these beliefs in turn directly affected posttest smoking reduction. The path diagram in Figure 1 illustrates the study hypotheses.

\section{METHOD}

A 1-year pretest/posttest quasi-experimental design was used for a secondary data analysis of a large-scale worksite health promotion project (Health Associates, Inc., 1984; Conrad, Riedel, \& Gibbs, 1988, 1990). The original study did not incorporate an examination of the role of health beliefs into the analysis of smoking behavior change. Besides proposing a modified conceptual framework, the secondary analysis differs from the original study in that a path analysis was 
Pretest

\section{One-Year Posttest}

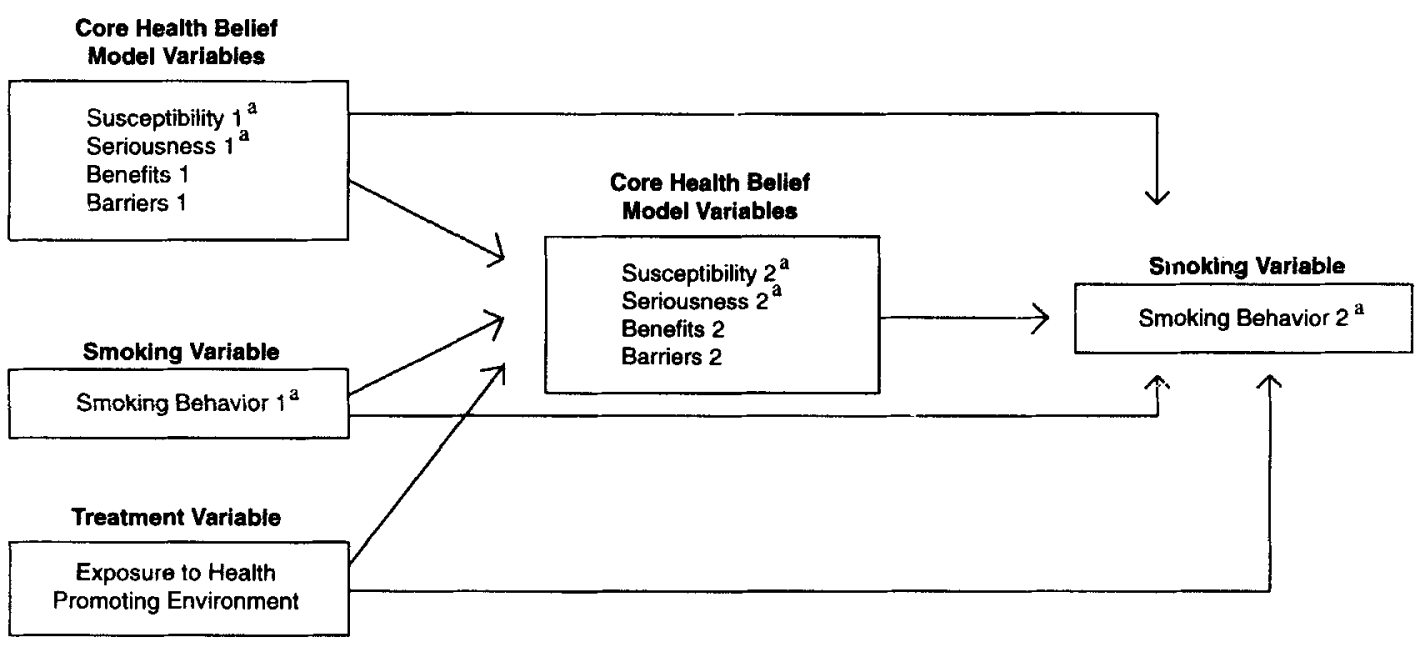

${ }^{\text {a }}$ Multiple Indicators - See Table 1

FIGURE 1. Preliminary path diagram of smoking behavior.

conducted using LISREL (Jöreskog \& Sörbom, 1993).

\section{Sample}

The sample consisted of workers employed by a large midwestern health insurance company who met the following inclusion criteria: (a) employed by the company a minimum of 6 months, (b) asymptomatic for cardiovascular disease and cancer, (c) completed a health and attitude survey and a consent form, and (d) reported they were smokers on the pretest survey.

The company employed a total of 5,417 workers. Of the 1,066 workers who met the first three eligibility criteria, $391(36 \%)$ reported that they were smokers on the pretest survey. At the 1-year posttest, 310 of the original 391 subjects remained in the study (the dropout rate was $21 \%$ ). Of the 310 cases available for analysis, 82 were in the treatment/exposure group located at one company building, and the remaining 228 were in the comparison group located at another company site. The buildings were geographically isolated.

Study subjects were primarily white $(68.1 \%)$, female $(69.0 \%)$, with one or more years of college education $(72.4 \%)$, and with a modal age category of $25-34$ years $(46.8 \%)$. The treatment/exposure group had a significantly larger percentage of whites, males, and better-educated members than the comparison group. Thus, group equivalence at pretest could not be assumed. A logistic analysis showed no significant systematic bias at posttest due to dropout status.

\section{Measures}

Items were selected from among general health belief scales in the existing data set that pertained to smoking or diseases that are related to smoking. Choosing such smoking-specific measures was thought to increase the likelihood of observing significant correlations between health beliefs and smoking. All variables were self-reported measures. The means, standard deviations, and internal consistency reliabilities for the multiple indicator variables are shown in Table 1. Reliabilities are above .80 for all measures except those for the pretest smoking behaviors.

Health beliefs. Perceived susceptibility is a three-item, seven-point scale that refers to an individual's subjective perception of the likelihood of contracting cancer, stroke, or a heart attack. The item stem read: "If you do nothing to prevent each of the following health problems, how likely do you think you are to get each one in the next 5 years?" The response options ranged from no chance at all to get (1) to almost certain to get (7). Perceived seriousness, also a three-item, 
Table 1. Performance of Scale Items Used to Measure Model Variables

\begin{tabular}{lccccc}
\hline Variable & No. of Items & $\begin{array}{c}\text { Response } \\
\text { Scale Range }\end{array}$ & Mean Score & SD & $\begin{array}{c}\text { Standardized } \\
\alpha \text { Coefficient }\end{array}$ \\
\hline Perceived susceptibility (T1) & 3 & $1-7$ & 10.01 & 3.88 & .82 \\
Perceived susceptibility (T2) & 3 & $1-7$ & 10.50 & 3.63 & .85 \\
Perceived seriousness (T1) & 3 & $1-7$ & 19.45 & 2.65 & .84 \\
Perceived seriousness (T2) & 3 & $1-7$ & 19.18 & 269 & .89 \\
Perceived barriers (T1) & 1 & $1-7$ & 5.30 & 1.87 & 2.12 \\
Perceived barriers (T2) & 1 & $1-7$ & 4.60 & 1.51 & 1.28 \\
Perceived benefits (T1) & 1 & $1-7$ & 5.75 & 5.88 & 1.18 \\
Perceived benefits (T2) & 1 & $1-7$ & 5.73 & 2.43 \\
Smoke behavior (T1) & 2 & $1-4$ & 4.27 & .42 \\
Smoke behavior (T2) & 2 & $1-4$ & & .87 \\
\hline
\end{tabular}

a Range for each item. $\mathrm{bT} 1=$ Time 1 pretest; $\mathrm{T} 2=$ Time 2 posttest.

seven-point scale, refers to an individual's subjective perceptions of the seriousness of contracting these three diseases. The item stem read: "If you were to get any of the following health problems, how much of a bad effect would it have on your life?" The response options ranged from little or no effect (1) to a very great effect (7). Perceived benefits, a one-item, seven-point scale, refers to an individual's subjective perception of the relative effectiveness of smoking cessation in reducing the likelihood of getting a heart attack. The item stem read: "Many people think there are things they can do to help prevent heart attacks. How much do you believe not smoking cigarettes can help prevent heart attacks?" The response options ranged from would do little or nothing to prevent (1) to would do a great deal to prevent (7). Perceived barriers is a one-item, seven-point scale that refers to an individual's subjective perception of the difficulty of quitting cigarette smoking. The item stem read: "If your doctor advised you to not smoke cigarettes, how difficult do you think it would be for you to do?" The response options ranged from not difficult at all (1) to extremely difficult (7). Internal consistency estimates of reliability range from .82 to .89 for the health belief measures. Unfortunately, only one indicator each was available for perceived benefits and perceived barriers, making it impossible to estimate internal consistency.

Smoking behavior. Smoking behavior is a two-item, four-point scale. The items ask about the number of cigarettes smoked per day $(<10$, $10-19,20-39$, and $\geq 40$ ) and the degree of smoke inhalation (not at all, just a little bit, moderately, and deeply). The pretest smoking behavior measure has an internal consistency reliability of .42 , whereas the reliability for the posttest smoking behavior measure rises to .87 . The authors hypothesize that the change in correlation structure over time may have been due to a program effect. That is, at posttest, the smokers more clearly understood that the smoking dose received is affected by both the number of cigarettes smoked and the degree of inhalation with each puff. This explanation is speculative, because knowledge about dose effects was not measured.

The treatment/exposure variable: $A$ cue to action. The treatment/exposure variable refers to whether an employee was exposed to a healthpromoting environment by working at the experimental site. The cues included risk reduction programs, personal health counseling, and printed health education materials. The risk reduction programs and number of employees who attended were: smoking cessation (21), stress management (224), physical fitness (108), weight control (56), cholesterol (14), blood pressure control (15), and medical self-care (20). A total of $57 \%$ requested the newsletters. An unknown percent of employees received health counseling. (Note that the attendance numbers represent both smokers and nonsmokers from the treatment site, because numbers for smokers only were not available).

Each of the risk reduction programs is briefly described. A choice of two different smoking cessation programs was available. Smoke-Stoppers offered a 12 -hr program featuring a variety of behavior modification activities. Monthly followup meetings were held with the buddy system providing social support between meetings. The second program was offered by a local hospital 
using the American Cancer Society quit smoking model. A two-part stress management program was offered. The initial program was $7 \mathrm{hr}$ in length and consisted of information on stress theory, self-evaluation, time management, and stress identification. Relaxation techniques were practiced. The second program emphasized practical techniques for reducing stress, including guided imagery.

Participants were offered a choice of two aerobic exercise programs: a YMCA program and a Dance-Fit class. The YMCA program was offered three times per week for 10 weeks. The Dance-Fit program offered three sessions over a 3-month period with classes held two to three times per week. Two weight control programs were offered. Slim Living was a YMCA-sponsored program that emphasized sound dietary decision making. The 14-hr program was offered twice a week for 5 weeks with a 4-hr followup. Weight Watchers was the second program offered. A 7-hr cholesterol control program was offered by a registered dietician from a local hospital. Evening programs were offered so that employee spouses could more easily attend. A 5-hr blood pressure control program was offered to hypertensive employees. Course content emphasized physiologic factors, medication, selfmonitoring, diet, and exercise. Follow-up monitoring was available. Finally, a 10-hr medical self-care program was offered at no charge.

The treatment exposure measure was designed to test whether a health-promoting environment acted as a cue to smoking reduction by creating a health milieu that triggered workers to reduce smoking, even if they did not actively participate in the activities. The exposure variable is a oneitem dichotomous measure of exposure to a worksite health promotion environment.

\section{Procedures}

Both the treatment/exposure and comparison groups completed a baseline health risk appraisal and a supplemental health survey that asked about the participants' personal health beliefs, lifestyle practices, and health histories. In addition, at the treatment site, employees were invited to participate in the risk reduction programs and health risk counseling and to receive health education materials. All risk reduction programs, with the exception of the exercise classes, were conducted in a "lunch and learn" format. Employees combined a $30-$ min lunch period with a 20 -min break, and the company added $10 \mathrm{~min}$ to round out the 1-hr segment. Programs supplied by outside vendors were offered at the worksite at no charge or nominal charge. At the 1-year posttest, participants completed the same health risk appraisal and supplemental health survey as at the pretest.

\section{RESULTS}

Data were analyzed by structural equation modeling using the LISREL 8 program. The LISREL model consists of two components or submodels: (a) a measurement (confirmatory factor) model specifying the linkages between observable and latent variables, and (b) a structural equation (path) model specifying a set of regression equations among the latent variables. In the measurement model, each observable variable is a function of a latent factor and an error term. The error term contains all influences on the observable variable not specified by the latent factor. The structural equation model involves regression relationships among the latent variables. In the analyses to follow, these two submodels are fit $s i$ multaneously rather than fitting the measurement model first, fixing it, and then estimating the structural equation model contingent on the measurement model. The basic measurement model, in terms of indicators of latent constructs, was described in the previous section and did not change across our various models.

The primary concern was whether the exposure variable had a statistically significant effect on smoking reduction. This effect was assessed in two ways: (a) as a direct effect, unmediated by intervening variables; and (b) as a total effect, i.e., an effect consisting of the direct effect plus all indirect effects via the intervening health belief variables. As noted previously, the treatment/exposure and comparison groups differed on some demographics. Prior analysis (not shown) showed the demographic variables to be nonsignificant predictors. Thus, in the interest of parsimony, the demographic variables were not entered into the model.

Because the same variables were measured at two points in time, it was important to test whether errors of measurement were correlated over time. Failure to control for such correlated errors would bias the estimates of structural coefficients. First, a LISREL model was fitted that assumed independence of errors. Then, that assumption was gradually relaxed by permitting the error term for one or more variables to correlate across time. In other words, the basic measurement model was the same in terms of the relation- 
Table 2. Comparative Goodness of Fit Among Three Models

\begin{tabular}{lccc}
\hline Goodness of Fit Measures & Model $1^{\mathrm{a}}$ & Model $2^{\mathrm{b}}$ & Model $3^{\mathrm{c}}$ \\
\hline Likelihood test $\left(\mathrm{x}^{2}\right)\left(L^{2}\right)$ & 386.4 & 278.1 & 211.8 \\
$d f$ & 149 & 147 & 144 \\
$\rho$ & $<.001$ & $<.001$ & $<.001$ \\
Root mean square residual & .073 & .069 & .062 \\
Goodness of fit index & .883 & .909 & .932 \\
Adjusted goodness of fit index & .801 & .844 & .880 \\
Normed fit index & .850 & .880 & .920 \\
Increment in $L^{2}$ & & 111.7 & 66.3 \\
$d f$ & & 2 & 3 \\
$p$ & & $<.001$ & $<.001$ \\
\hline
\end{tabular}

aModel 1 assumed no correlated error. bModel 2 assumed two correlated errors: between Cigarettes per Day at Times 1 and 2, and between Cigarettes per Day at Time 1 and Inhale at Time 2. cModel 3 assumed the two correlated errors in Model 2 and three new correlated errors: between Susceptibility (Cancer) at Times 1 and 2, between Serious (Heart Attack) at Times 1 and 2, and between Serious (Stroke) at Times 1 and 2.

ship of observable variables to latent constructs, but the pattern of error correlations was allowed to vary. It is largely an empirical question as to which variables might be affected. LISREL provides a modification index, which shows what will happen to the overall goodness of fit statistic if a particular parameter (i.e., a correlated error) previously set to zero is relaxed. This information was used to help fit a sequence of three models to the data.

The goodness of fit results for a series of three LISREL models are shown in Table 2. Model 1, the baseline model, assumed that there were no correlated errors over time. The likelihood ratio statistic $\left(L^{2}\right)$, which is the measure of overall fit, was highly significant, indicating a poor fit of the model to the data. Other goodness of fit statistics also indicate a poor fit; for example, the normed fit index was $<.9$. Model 2 assumed two correlated errors involving smoking measures at pretest and posttest (i.e., between Cigarettes per Day at Times 1 and 2 and between Cigarettes per Day at Time 1 and Inhale at Time 2). The basic measurement model results involving the estimates of loadings of observable variables on latent constructs were essentially unchanged. There was a significant improvement in model fit as shown by the significant difference in the $L^{2}$ statistic between models. Other goodness of fit statistics showed improvement in model fit; however, the normed fit index was still below 9 .

Model 3 assumed five correlated errors: the two correlated errors in Model 2 and three new correlated errors among the health belief measures. The three new correlated errors were: between Susceptibility (Cancer) at Times 1 and 2, between Serious (Heart Attack) at Times 1 and 2, and between Serious (Stroke) at Times 1 and 2 . Again, the basic measurement model results were essentially unchanged. There was a significant difference in the $L^{2}$ statistic between Models 2 and 3 , indicating an improvement in model fit. In Model 3, the goodness of fit statistics improved and the normed fit index reached .92 , an acceptable level.

Model 3 was judged to fit the data for several reasons. First, as discussed in more detail later, estimates of the treatment effect were quite stable across models. Second, it is well known that departures from multivariate normality as well as the use of quasi-interval scale measures tend to mitigate against finding a good fit to the model, driving the chi-square statistic up. However, lack of fit due to distribution problems does not result in biased coefficients (Bentler \& Bonett, 1980). Finally, the residuals from the model were approximately normally distributed. This, combined with the facts that the modification indices for the remaining possible correlated errors were small and that the changes made from Model 2 to Model 3 resulted in virtually no change in the structural parameters, led to the conclusion that although eventually a model could be found that fit the data at a higher level, it would be done at the cost of introducing numerous nuisance parameters-small correlated errors that would not affect the interpretation of the results.

Across these three models, the basic estimates of program effect were essentially unchanged, as shown in Table 3 . Looking at the direct effects, there was about a $16 \%$ drop in the standardized estimate of the program effect between Model 1 
Table 3. Decomposition of Intervention Effect Across Models

\begin{tabular}{lccc}
\hline Intervention Effect & Model $1 \mathrm{a}$ & Model $2^{\mathrm{b}}$ & Model $3^{\mathrm{c}}$ \\
\hline Direct effect & -.388 & -.326 & -.328 \\
$\quad t$ value & -2.76 & -2.67 & -2.68 \\
$\quad-.241$ & -.250 & -.249 \\
Indirect effect & -2.17 & -2.23 & -2.22 \\
$\quad t$ value & -.628 & -.576 & -.577 \\
Total effect & -3.38 & -3.47 & -3.48 \\
$t$ value & &
\end{tabular}

aModel 1 assumed no correlated error. bModel 2 assumed two correlated errors: between Cigarettes per Day at Times 1 and 2, and between Cigarettes per Day at Time 1 and Inhale at Time 2. cModel 3 assumed the two correlated errors in Model 2 and three new correlated errors: between Susceptibility (Cancer) at Times 1 and 2, between Serious (Heart Attack) at Times 1 and 2, and between Serious (Stroke) at Times 1 and 2 .

and Model 2, reflecting the adjustment to bias caused by correlated errors of measurement. There was essentially no change in the effect between Model 2 and Model 3, even though the overall improvement in goodness of fit was significant. Essentially the same results held for the total effect. The final statistical tests on all effect measures, direct, indirect, and total, were significant.

In summary, we found a program effect under widely varying assumptions about correlated errors of measurement. These results show a pattern that is fairly common in the LISREL literature-that estimates for structural equations are not highly dependent on specification of correlated errors, and that allowing correlated error does not affect the basic measurement model results. For example, Campbell and Mutran (1982) showed that estimates for the structural equation part of a complex longitudinal model were impervious to the specification of the correlated errors, changing by less than $10 \%$ regardless of measurement model specification.

The results from the final model, including standardized factor loadings and structural coefficients, are shown in Figure 2. All factor loadings involving variables with multiple indicators exceeded .40 and ranged from .41 to .91 . There were 11 statistically significant $(p \leq .05)$ structural paths among the latent constructs in the final model.

The primary dependent variable was posttest smoking behavior. Among the hypothesized determinants, significant negative effects were observed for pretest perceived barriers and the exposure variable $(1=$ treatment/exposure group; 0 = comparison group). Significant positive net ef- fects were observed for pretest smoking behavior and posttest perceived barriers $\left(R^{2}=.744\right)$. Smokers reduced their smoking amount by decreasing the number of cigarettes they smoked per day and/or decreasing the amount they inhaled. Both smoking reduction and quitting were higher in the treatment/exposure group than in the comparison group. In all, 50 smokers reported quitting $(24.4 \%$ of the treatment/exposure group and $13.2 \%$ of the comparison group).

With the exception of the pretest perceived barriers variable, all effects were consistent with theoretical expectations. The authors hypothesize that the incorrect sign for the pretest barrier effect was a spurious effect, because the zero-order correlation between it and posttest smoking behavior was positive $(r=.26, p<.0001)$. To test for systematic bias due to missing pretest smoking data, a dummy variable was entered into the equation. The significant negative effect observed for the dummy variable meant that cases were not missing randomly. Those who did not respond to the pretest smoking questions tended to smoke less at posttest than those who responded at both times. Thus, the systematic bias was not toward heavier smokers not providing complete data.

In addition to the determinants of posttest smoking behavior, the determinants of posttest health beliefs were also examined. The first three health beliefs-susceptibility, seriousness, and benefits-were predicted only by their pretest measure. Pretest barriers had a significant positive effect on posttest barriers. The exposure variable and the dummy variable used to indicate missing pretest smoking data each showed significant negative net effects. These latter two net effects can be interpreted to mean that individuals exposed to the health-promoting environment reported less perceived difficulty quitting at the posttest than did those workers not exposed to that environment. Also, those individuals with missing pretest smoking data reported greater perceived difficulty with quitting on the posttest than did those individuals with complete smoking data.

\section{DISCUSSION}

Results suggest that exposure to a health-promoting worksite environment reduced smoking behavior. The finding of this effect supports other study conclusions (Dawley, Dawley, Glasgow, Rice, \& Correa, 1993; Erfurt, Foote, \& Heirich, 1991; Jeffery et al., 1993; Glasgow et al., 1993; 


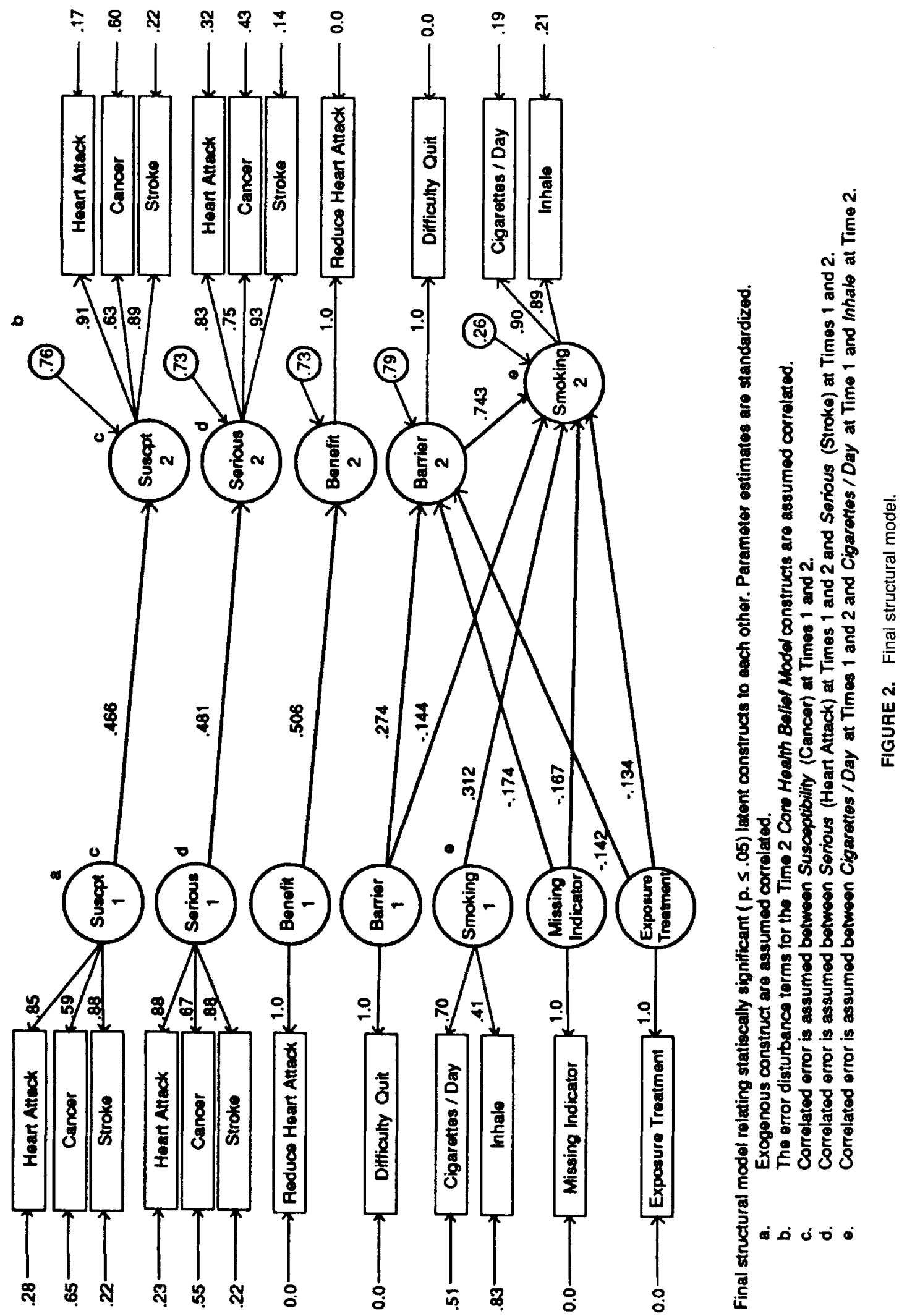


Shipley et al., 1988). The health-promoting environment significantly reduced smoking behavior both directly and indirectly by altering the perceived difficulty of quitting. This finding of an indirect treatment/exposure effect suggests that the company was in fact successful in its efforts to alter perceived health beliefs.

Several study strengths and limitations deserve mention. Measurement error among the observable multiple-item variables was controlled using LISREL, thus enabling a more precise estimate of the regression coefficients. The LISREL program also provided a goodness of fit test that allowed the testing of the baseline model as well as testing for improvement across models when correlated errors were estimated. In this way, the investigators were able to assess the model's congruence with the observed data. Multivariate analysis was used to control for the pretest measure of smoking behavior, thereby strengthening the inference of a treatment/exposure effect.

Because of the voluntary nature of worksite health promotion programs, selection bias remains a major validity threat to the conclusion that exposure to a health-promoting program or environment reduced the targeted behavior (Conrad, Conrad, \& Walcott-McQuigg, 1991). This study was subject to the same threat, although an attempt was made to control for pretest group nonequivalence by entering pretest smoking behavior into the analysis. As previously noted, demographic variables did not have statistically significant independent effects on posttest smoking. In terms of attrition, $21 \%$ of the study participants dropped out after 1 year. However, logistic regression showed that group membership was not a significant predictor of dropout status.

The assumption of multivariate normality was likely violated. Mono-operation bias was a threat for those variables that were measured with single-item indicators, e.g., benefits, barriers, and the exposure/treatment variable. Smoking status was not verified biochemically. However, the conclusion drawn from a recent meta-analysis of studies examining the validity of self-reported smoking was that self-reports of smoking are accurate in most studies (Patrick et al., 1994). When the target group is all smokers, obtaining validated smoking behavior measures is not very feasible. An unfortunate problem common to worksite studies and one present in this study is the limited number of worksites available for comparison. Ideally, the unit of analysis in studies examining characteristics of the worksite environment should be the worksite (Glasgow et al., 1992). Future studies will need to use multi- ple study sites, beyond the two sites available in this study (Koepke \& Flay, 1989).

An existing data base was used to answer the research questions. The researchers had access to data on a major, large-scale worksite health promotion program in which careful data quality controls had been maintained. A disadvantage of using archival data is that the researchers are limited in the questionnaire items available for analysis (Kiecolt \& Nathan, 1985). Some variables could be measured with only single items. Detailed archival records were not kept on program participation. Also, because the researchers were removed from the program and data collection period, they had no way of investigating why missing items may have occurred. Still, the data available were able to suggest useful information about the importance of the worksite environment in promoting smoking reduction.

The data are over a decade old. Smoking prevalence rates have dipped and social norms about smoking have changed since the data were collected. Still, the problem of smoking remains the primary preventable problem in this country, as many workers continue to initiate and maintain smoking. The risk reduction programs offered today are similar to the ones offered at this company. New and relevant is the growing awareness among the worksite health promotion research community that efforts to decrease smoking require a much broader environmental or ecological approach than is typically now used. The empirical data base required to support this position is just now beginning to surface. The results of this study add to this data base and serve to illustrate that there is likely a benefit in taking an environmental intervention approach.

The study findings suggest that the role of the worksite environment in promoting health merits further exploration. Pender (1989) noted that "research is needed to identify environmental parameters that can be modified to strengthen health and increase the frequency of health-enhancing behavior in work settings" (p. 40). Future research may consider integrating theoretical models to include both those that focus on the individual, such as the HBM, and those that encompass environmental determinants (DeJoy \& Southern, 1993; Green \& Kreuter, 1991; McLeroy, Bibeau, Steckler, \& Glanz, 1988).

Furthermore, multiple indicators of the worksite environment are needed to capture more completely such components as social norms at the worksite regarding smoking, health policies (including smoking and respiratory exposure policies), nonsmoking campaigns in the worksite, 
health education materials, reduction programs, and degree of management support for health promotion initiatives.

Smoking is an intricately complex behavior. The reasons for its initiation are not clearly understood (Conrad, Flay, \& Hill, 1992). For some smokers, complete cessation may not be a viable choice, but smoking reduction may be a reasonable first goal (Bertera, Oehl, \& Telepchak, 1990; Hajek, 1991). Although complete cessation of smoking is preferred, sustained reduction is likely to reduce the risk of disease and is a valuable public health outcome (Chapman, Borland, Hill, Owen, \& Woodward, 1990; Wakefield, Wilson, Owen, Esterman, \& Roberts, 1992). Health-promoting environments that assist with smoking reduction as well as complete cessation will allow more employees to meet at least intermediate goals. Finally, the finding that barriers (operationalized as perceived difficulty in quitting) was a strongly significant predictor of smoking reduction suggests the need to explore those aspects of the reduction process that are particularly difficult and to tailor strategies to reduce those barriers.

\section{REFERENCES}

Becker, M.H., \& Maiman, L.A. (1975). Sociobehavioral determinants of compliance with health and medical care recommendations. Medical Care, $13,10-24$.

Bentler, P.M., \& Bonett, D.G. (1980). Significance tests and goodness-of-fit in the analysis of covariance structures. Psychological Bulletin, 88, 588600.

Bertera, R.L., Oehl, L.K., \& Telepchak, J.M. (1990). Self-help versus group approaches to smoking cessation in the workplace: Eighteen-month follow-up and cost analysis. American Journal of Health Promotion, 4, 187-192.

Campbell, R.T., \& Mutran, E. (1982). Analyzing panel data in studies of aging: Applications of the LISREL Model. Research on Aging, 4, 3-41.

Chapman, S., Borland, R., Hill, D., Owen, N., \& Woodward, S. (1990). Why the tobacco industry fears the passive smoking issue. International Journal of Health Services, 20, 417-427.

Chen, M., \& Land, K. (1986). Testing the Health Belief Model: LISREL analysis of alternative models of causal relationships between health beliefs and preventive dental behavior. Social Psychology Quarterly, 49, 45-60.

Conrad, K.M., Conrad, K.J., \& Walcott-McQuigg, J. (1991). Threats to internal validity in worksite health promotion program research: Common problems and possible solutions. American Journal of Health Promotion, 6, 112-121.
Conrad, K.M., Flay, B.R., \& Hill, D. (1992), Why children start smoking: Predictors of onset. British Journal of Addiction, 87, 1711-1724.

Conrad, K.M., Riedel, J.E., \& Gibbs, J.O. (1988). Health promotion: A new direction in health care. Chicago: Blue Cross and Blue Shield Association, Health Services Foundation.

Conrad, K.M., Riedel, J.E., \& Gibbs, J.O. (1990). Effect of worksite health promotion programs on employee absenteeism: A comparative analysis. AAOHN Journal, 38, 573-580.

Dawley, L.T., Dawley, H.H., Glasgow, R.E., Rice, J., \& Correa, P. (1993). Worksite smoking control, discouragement, and cessation. International Journal of the Addictions, 28, 719-733.

DeJoy, D.M., \& Southern, D.J. (1993). An integrative perspective on worksite health promotion. Journal of Occupational Medicine, 35, 1221-1230.

Erfurt, J.C., Foote, A., \& Heirich, M.A. (1991). Worksite wellness programs: Incremental comparison of screening and referral alone, health education, follow-up counseling, and plant organization. American Journal of Health Promotion, 5, 438-448.

Fielding, J.E. (1986). Smoking: Health effects and control. In J.M. Last (Ed.), Public health and preventive medicine (pp. 999-1038). Norwalk, CT: Appleton-Century Crofts.

Fisher, K.J., Glasgow, R.E., \& Terborg, J.R. (1990). Worksite smoking cessation: A meta-analysis of quit rates from controlled studies. Journal of Occupational Medicine, 32, 429-439.

Flay, B.R. (1987). Mass media and smoking cessation: A critical review. American Journal of Public Health, 77, 153-160.

Glasgow, R.E., Hollis, J.F., Ary, D.V., \& Boles, S.M. (1993). Results of a year-long incentivesbased worksite smoking-cessation program. Addictive Behaviors, 18, 455-464.

Glasgow, R.E., Sorensen, G., \& Corbett, K. (1992). Worksite smoking control activities: Prevalence and related worksite characteristics from the COMMIT study, 1990. Preventive Medicine, 21, 688-700.

Glynn, T.J., Boyd, G.M., \& Gruman, J.C. (1990). Essential elements of self-help/minimal intervention strategies for smoking cessation. Health Education Quarterly, 17, 329-345.

Green, L.W., \& Kreuter, M.W. (1991). Health promotion planning: An educational and environmental approach. Mountain View, CA: Mayfield.

Hajek, P. (1991). Individual differences in difficulty quitting smoking. British Journal of Addiction, 86. 555-558.

Health Associates, Inc. (1984), Go to health. Chicago: Blue Cross and Blue Shield Association, Health Services Foundation.

Hymowitz, N., Campbell, K., \& Feuerman, M. (1991). Long-term smoking intervention at the worksite: Effects of quit-smoking groups and an "enriched milieu" on smoking cessation in adult white-collar employees. Health Psychology, 10, 366-369. 
Institute for Health Policy, Brandeis University. (1993). Substance abuse: The nation's number one health problem. Princeton, NJ: Robert Wood Johnson Foundation.

Jeffery, R.W., Forster, J.L., French, S.A., Kelder, S.H., Lando, H.A., McGovern, P.G., Jacobs, D.R., \& Baxter, J.E. (1993). The Healthy Worker Project: A work-site intervention for weight control and smoking cessation. American Journal of Public Health, 83, 395-401.

Jöreskog, K.G., \& Sörbom, D. (1993). DOS Extender LISREL (Version 8.02) [Computer software]. Chicago: Scientific Software, Inc.

Kiecolt, K.J., \& Nathan, L.E. (1985). Secondary analysis of survey data. Beverly Hills, CA: Sage.

Knight, R.A., \& Hay, D.A. (1989). The relevance of the Health Belief Model to Australian smokers. Social Science in Medicine, 28, 1311-1314.

Koepke, D., \& Flay, B.R. (1989). Levels of analysis. New Directions for Program Evolution, 43, 75-88.

Mcllvain, H.E., McKinney, M.E., Thompson, A.V., \& Todd, G.L. (1992). Application of the MRFIT smoking cessation program to a healthy, mixed-sex sample. American Journal of Preventive Medicine, 8, 165-174.

McLeroy, K.R., Bibeau, D., Steckler, A., \& Glanz, K. (1988). An ecological perspective on health promotion programs. Health Education Quarterly, 15 , 351-377.

Nelson, D.E., Emont, S.L., Brackbill, R.M., Cameron, L.L., Peddicord, J., \& Fiore, M.C. (1994). Cigarette smoking prevalence by occupation in the United States. Journal of Occupational Medicine, 36, 516-525.

Patrick, D.L., Cheadle, A., Thompson, D.C., Diehr, P., Koepsell, T., \& Kinne, S. (1994). The validity of self-reported smoking: A review and meta-analysis. American Journal of Public Health, 84, 1086-1093.

Pender, N.J. (1989). Health promotion in the workplace: Suggested directions for research. American Journal of Health Promotion, 3, 38-43.

Rosenstock, I.M. (1966). Why people use health ser- vices. Millbank Memorial Fund Quarterly, 44, 94124.

Rosenstock, I.M. (1990). The Health Belief Model: Explaining health behavior through expectancies. In K. Glanz, F.M. Lewis, \& B.K. Rimer (Eds.), Health behavior and health education (pp. 39-62). San Francisco: Jossey-Bass.

Shipley, R.H., Orleans, C.T., Wilbur, C.S., Piserchia, P.V., \& McFadden, D.W. (1988). Effect of the Johnson \& Johnson Live for Life program on employee smoking. Preventive Medicine, 17, 25-34

Sorensen, G., Lando, H., \& Pechacek, T.F. (1993). Promoting smoking cessation at the workplace. Journal of Occupational Medicine, 35, 121-126.

Sörbom, D., \& Jöreskog, K.G. (1981). The use of LISREL in sociological model building. In D.J. Jackson \& E.F. Borgatta (Eds.), Factor analysis and measurement in sociological research (pp. 179199). Beverly Hills, CA: Sage.

Stacy, R.D., \& Loyd, B.H. (1990). An investigation of beliefs about smoking among diabetes patients: Information for improving cessation efforts. Patient Education and Counseling, 15, 181-189.

United States Department of Health and Human Services. (1990). Healthy people 2000: National health promotion and disease prevention objectives (DHHS Publication No. PHS 91-50212). Washington DC: U.S. Government Printing Office.

United States Department of Health and Human Services. (1993). 1992 national survey of worksite health promotion activities: Summary. American Journal of Health Promotion, 7, 452-462.

United States Public Health Service. (1964). Smoking and health: Report of the Advisory Committee to the Surgeon General of the Public Health Service. (PHS Publication No. PHS 1103). Rockville, MD: Author.

Wakefield, M.A., Wilson, D., Owen, N., Esterman, A., \& Roberts, L. (1992). Workplace smoking restrictions, occupational status, and reduced cigarette consumption. Journal of Occupational Medicine, 34, 693-697. 